\title{
Synthesis of 1,1'-methylenebis(1,2,4-triazole) functionalized in the methylene bridge. A new approach to dendrons bearing heterocyclic rings on the periphery
}

\author{
Enrique Díez-Barra,* Javier Guerra, Valentín Hornillos, Sonia Merino, \\ Julián Rodríguez-López, Prado Sánchez-Verdú, Juan Tejeda,* and Juan Tolosa \\ Facultad de Química, Universidad de Castilla-La Mancha, 13071 Ciudad Real, Spain \\ E-mail: juan.tejeda@uclm.es
}

\begin{abstract}
Dedicated to Professor José Elguero on the occasion of his $70^{\text {th }}$ birthday and to Professor Pedro Molina on the occasion of his $60^{\text {th }}$ birthday
\end{abstract}

(received 23 Dec 04; accepted 25 Feb 05; published on the web 13 Mar 05)

\begin{abstract}
3,3-Bis(1,2,4-triazol-1-yl)-1-propanol was obtained by reduction of its methyl carboxylate derivative. This compound is able to form the first generation dendron containing two bis(1,2,4triazol-1-yl)methyl systems on the periphery by reaction of its mesylate derivative with 3,5dihydroxybenzyl alcohol.
\end{abstract}

Keywords: Heterocyclic dendrons, 1,2,4-triazole, polyethers

\section{Introduction}

$1,1^{\prime}$-Methylenebis(1,2,4-triazole) is a useful compound in coordination chemistry owing to its ability to form $N, N$-complexes ${ }^{1}$ and biscarbenes that are able to coordinate transition metals. ${ }^{2}$ Functionalization of the methylene bridge would enable this compound to be transformed into bidentate ligands with a focal group, which should allow this structure to be incorporated into different macromolecules such as polymers or dendrimers. Although several methodologies have been described for the preparation of bridge-functionalized 1,1'-methylenedipyrazole and 1,1'methylenediimidazole, ${ }^{3}$ the use of these systems in the synthesis of 1,2,4-triazole derivatives still remains a desirable goal. To the best of our knowledge, only two such examples have been described and these are 4-[bis(1,2,4-triazol-1-yl)methyl]phenol ${ }^{4}$ (1) and methyl 3,3-bis(1,2,4triazol-1-yl)propionate ${ }^{3}$ (2). Compound 1 was coupled to 1,3,5-tris(chlorocarbonyl)benzene to give a system that is a precursor for $\mathrm{N}$-heterocyclic carbenes (NHC). However, further exploitation of this compound was not possible, probably due to the ease with which the benzylic methine bearing two triazole rings can be cleaved. ${ }^{5}$ For this reason we chose compound 2 , in 
which the presence of a benzylic position has been avoided in order to perform convergent dendritic growth using a Fréchet methodology. ${ }^{6}$ Thus, transformation of the ester group into either a bromide or sulfonate derivative - both of which can be efficiently substituted by phenoxy groups - is necessary.

In this paper we describe the synthesis of hydroxyl, bromide and mesylate $(\mathbf{3}, \mathbf{4}$ and $\mathbf{5})$ derivatives starting from the aforementioned ester $\mathbf{2}$. The coupling of mesylate $\mathbf{5}$ with 3,5dihydroxybenzyl alcohol to give the first generation dendron 7 is also described.

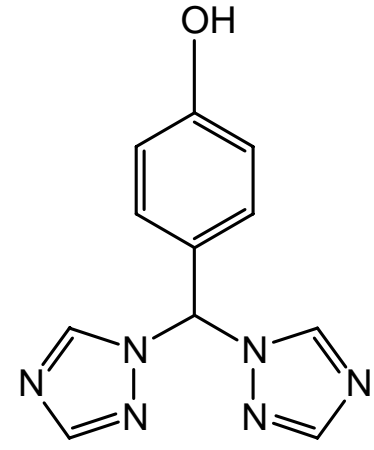

1

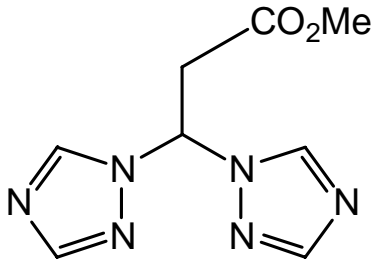

2

\section{Figure 1}

\section{Results and Discussion}

Methyl 3,3-bis(1,2,4-triazol-1-yl)propionate (2) was obtained by a double Michael addition of 1,2,4-triazole to methyl propiolate. ${ }^{3}$ Attempts to reduce the ester group using lithium aluminum hydride in refluxing THF or borane-methyl sulfide complex resulted in complete decomposition of the starting materials. However, 3,3-bis(1,2,4-triazol-1-yl)propanol (3) could be obtained in good yield (70\%) using a large excess of lithium aluminum hydride in THF at $-60{ }^{\circ} \mathrm{C}$ for $25 \mathrm{~min}$. (Scheme 1). Evidence for the formation of $\mathbf{3}$ was provided by ${ }^{1} \mathrm{H}$ NMR spectroscopy. The spectrum did not contain a signal for a methyl group and two doublet of triplets were observed at 3.60 and $2.84 \mathrm{ppm}$, which are assigned to the protons of the two methylene groups (coupling with the hydroxylic proton is observed).

The bromide derivative 4 was prepared by treatment of alcohol 3 with 4 equivalents of carbon tetrabromide and 4 equivalents of triphenylphosphine in acetonitrile at $\mathrm{rt}$ for $24 \mathrm{~h}$. Purification of the product proved difficult and it could only be obtained in moderate yield (maximum 40\%). On the other hand, the hydroxyl group of $\mathbf{3}$ was transformed into the corresponding mesylate derivative in $96 \%$ yield by reaction with 1.5 equivalents of $\mathrm{MsCl}$ and $\mathrm{Et}_{3} \mathrm{~N}$ in THF at $\mathrm{rt}$ for $2 \mathrm{~h}$. A ${ }^{1} \mathrm{H}$ NMR signal at $3.03 \mathrm{ppm}$ - assigned to the methyl group in the spectrum of $\mathbf{5}$ - supports the structure of this product. 


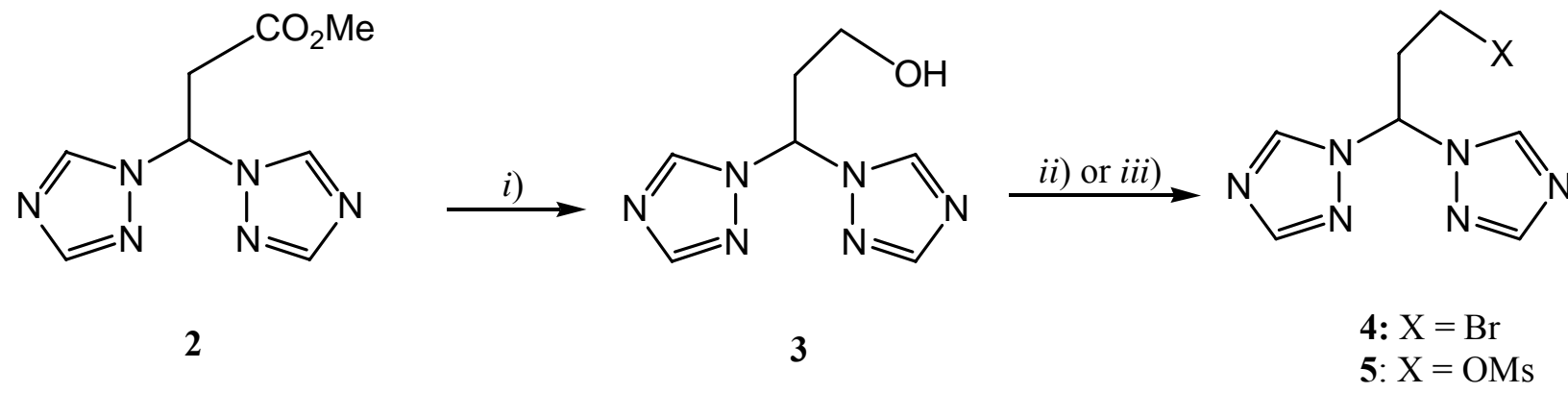

Scheme 1. (i) $\mathrm{LiAlH}_{4}$ (excess), THF, $-60{ }^{\circ} \mathrm{C}, 25 \mathrm{~min}$, then $\mathrm{H}_{2} \mathrm{O}, 70 \%$. (ii) $\mathrm{CBr}_{4}$ (4 eq), $\mathrm{PPh}_{3}$ (4 eq), $\mathrm{CH}_{3} \mathrm{CN}, \mathrm{rt}, 24$ h, 40\%. (iii) $\mathrm{MsCl}$ (1.5 eq), $\mathrm{Et}_{3} \mathrm{~N}$ (1.5 eq), THF, rt, 2 h, 96\%.

The first generation dendron 7 was obtained in $75 \%$ yield by reaction of 5 with 0.5 equivalents of 3,5-dihydroxybenzyl alcohol using an excess of potassium carbonate and a catalytic amount of 18-crown-6 (18-C-6) (Scheme 2) in THF refluxed for $16 \mathrm{~h}$.. The ${ }^{1} \mathrm{H}$ NMR spectrum of 7 contained a doublet at $6.46 \mathrm{ppm}$ and a triplet at $6.22 \mathrm{ppm}$. These signals are assigned to the protons of the benzene ring. The peaks due to the two branches appear as one group of signals and this observation is consistent with a symmetric structure. The protons of the triazole rings and the hydrogen of the bridge have chemical shifts similar to those of $\mathbf{3}$, although the signals for the aliphatic protons of the side arms are observed at higher chemical shifts. The signal for the benzylic protons appears at $4.61 \mathrm{ppm}$ as a singlet. The structure of this compound was also confirmed by ${ }^{13} \mathrm{C}$ NMR spectroscopy. The spectrum contains signals at 100.6 and 105.5 ppm for the para and ortho carbons, respectively, and 159.2 and 144.1 for the ipso and meta carbons of the benzene ring. A peak for the molecular ion was observed at $\mathrm{m} / \mathrm{z} 492.2$ (EI-MS) and matches the calculated molecular mass.

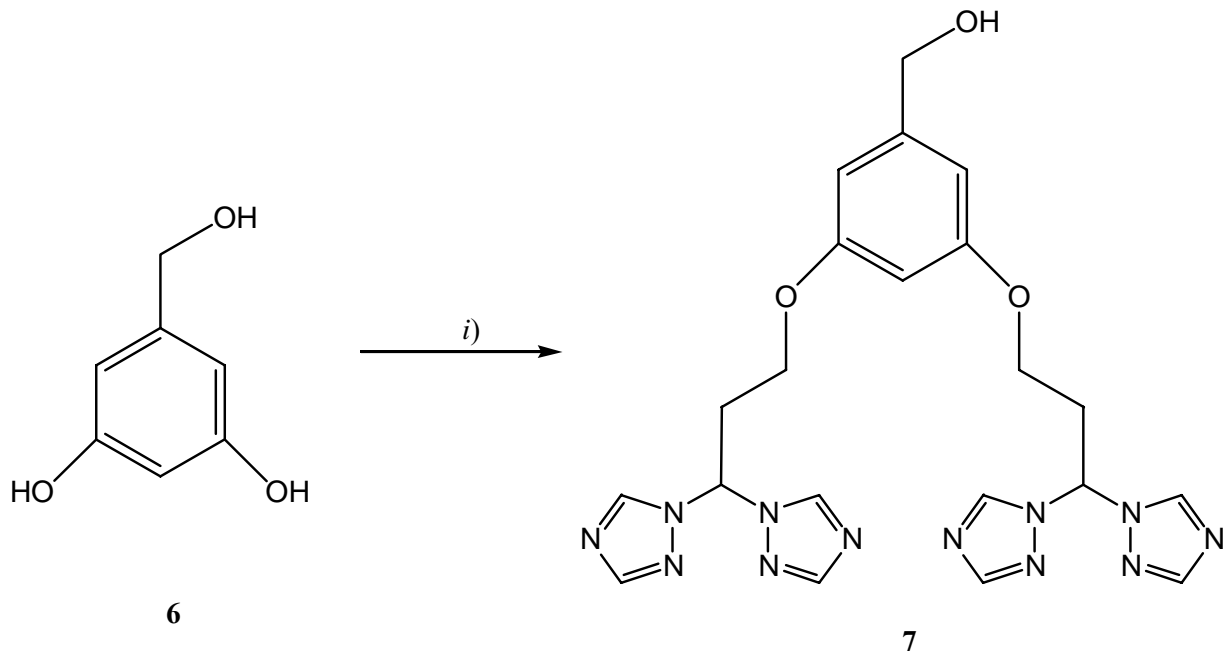

Scheme 2. i) 5 (0.5 eq), $\mathrm{K}_{2} \mathrm{CO}_{3}$ (excess), 18-C-6 (cat.), THF, reflux, 16 h, 75\%. 


\section{Conclusions}

A first generation dendron containing two bis(1,2,4-triazol-1-yl)methyl systems on the periphery can be prepared by reaction of mesylate 5 with 3,5-dihydroxybenzyl alcohol.

Experiments involving the further elaboration of dendron 7 in the synthesis of $\operatorname{poly}(\mathrm{N}$ heterocyclic carbenes) are now in progress in our laboratories.

\section{Experimental Section}

General Procedures. Solvents were purified by distillation from appropriate drying reagents before use. All reagents were used as received and without further purification. When necessary, work was carried out using standard Schlenk techniques under an atmosphere of dry argon. Melting points were determined in capillary tubes on a Gallenkamp apparatus and are uncorrected. Elemental analyses were performed on a Perkin-Elmer $2400 \mathrm{CHN}$ microanalyzer. Electron Impact (EI) (working at $70 \mathrm{~V}$ and $200{ }^{\circ} \mathrm{C}$ ) experiments were performed on a VG Autospec instrument belonging to Servicio Interdepartamental de Investigación, Universidad Autónoma de Madrid. IR spectra were recorded on a Nicolet 550 spectrophotometer (FT-IR). NMR spectra were recorded in $\mathrm{CDCl}_{3}$ on a Varian Inova-500 instrument with TMS or the solvent carbon signal as the standards, operating at $500 \mathrm{MHz}$ for ${ }^{1} \mathrm{H}$ and $125 \mathrm{MHz}$ for ${ }^{13} \mathrm{C}$. Chemical shift are expressed in parts per million $(\delta)$. The signals were assigned with the help of difference NOE and Hetcor experiments.

3,3-Bis(1,2,4-triazol-1-yl)-1-propanol (3). A solution of $2(2.50 \mathrm{~g}, 11.25 \mathrm{mmol})$ in THF $(50 \mathrm{~mL})$ was slowly added to a mixture of $\mathrm{LiAlH}_{4}(533 \mathrm{mg}, 14.04 \mathrm{mmol})$ and THF $(5 \mathrm{~mL})$ at $60{ }^{\circ} \mathrm{C}$. The reaction mixture was stirred at that temperature for $25 \mathrm{~min}$. The excess $\mathrm{LiAlH}_{4}$ was hydrolyzed by careful addition (dropwise) of water $(300 \mu \mathrm{L})$. The cooling bath was then removed and the solution allowed to warm up to room temperature. The solution was concentrated under vacuum until the volume was $20 \%$ of the original volume. The resulting material was centrifuged and decanted. The remaining white solid was stirred with several portions of THF $(3 \times 20 \mathrm{~mL})$ in order to extract the maximum amount of the absorbed product. The combined organic extracts were dried over $\mathrm{Na}_{2} \mathrm{SO}_{4}$ and the solvent removed under vacuum to afford the title alcohol $\mathbf{3}$ as a yellow oil. The pure product was obtained as a colorless solid after crystallization from $\mathrm{CHCl}_{3}$. Yield 70\%. mp 128-130 ${ }^{\circ} \mathrm{C}$. IR $\left(\mathrm{KBr}, \mathrm{cm}^{-1}\right): 3276(\mathrm{O}-\mathrm{H}), 1504$, 1282, 1135. ${ }^{1} \mathrm{H}$ NMR: 1.86 (t, $\left.J=4 \mathrm{~Hz}, 1 \mathrm{H}, \mathrm{OH}\right), 2.84\left(\mathrm{dt}, J=5.8 \mathrm{~Hz}, 7.4 \mathrm{~Hz}, 2 \mathrm{H}, \mathrm{CH}_{2} \mathrm{CH}_{2} \mathrm{OH}\right.$ ), $3.60\left(\mathrm{dt}, J=5.8 \mathrm{~Hz}, 4.7 \mathrm{~Hz}, 2 \mathrm{H}, \mathrm{CH}_{2} \mathrm{OH}\right), 6.95(\mathrm{t}, J=7.4 \mathrm{~Hz}, 1 \mathrm{H}, \mathrm{CHTz})_{2}, 7.98[\mathrm{~s}, 2 \mathrm{H}, \mathrm{H} 3$ (Tz)], 8.39 [s, 2H, $\mathrm{H} 5(\mathrm{Tz})] .{ }^{13} \mathrm{C}$ NMR: $35.9\left(\mathrm{CH}_{2} \mathrm{CH}_{2} \mathrm{OH}\right), 57.1\left(\mathrm{CH}_{2} \mathrm{OH}\right), 68.7\left(\mathrm{CHTz}_{2}\right), 142.9$ [C5 (Tz)], 152.4 [C3 (Tz)]. MS (EI), m/z: 150, $176.0\left[\mathrm{M}-\mathrm{H}_{2} \mathrm{O}\right]^{+}$. Anal. Calc. for $\mathrm{C}_{7} \mathrm{H}_{10} \mathrm{~N}_{6} \mathrm{O}$ (194.19): C, 43.29; H, 5.19; N, 43.28\%. Found: C, 43.09; H, 5.08; N, 43.47\%. 
1,1'-(3-Bromopropylidene)bis(1,2,4-triazole) (4). To a solution of 3 (400 mg, $2.06 \mathrm{mmol}$ ) and carbon tetrabromide $(2.73 \mathrm{~g}, 8.24 \mathrm{mmol})$ in acetonitrile $(30 \mathrm{~mL})$ was added a solution of triphenylphosphine $(2.16 \mathrm{~g}, 8.24 \mathrm{mmol})$ in acetonitrile $(20 \mathrm{~mL})$. The reaction mixture was stirred under argon for $24 \mathrm{~h}$ at room temperature. Potassium carbonate $(1 \mathrm{~g})$ was added and stirring was maintained until the organic layer had been neutralized $(15 \mathrm{~min})$. The crude mixture was filtered and the solvent evaporated under vacuum. The residue was purified by chromatography $\left(\mathrm{SiO}_{2}\right.$, hexanes/ethyl acetate, 1:10) followed by crystallization from $\mathrm{CH}_{2} \mathrm{Cl}_{2} / \mathrm{Et}_{2} \mathrm{O}$. Compound 4 was obtained as a colorless solid. Yield $40 \%$. mp 122-124 ${ }^{\circ} \mathrm{C}$. IR $\left(\mathrm{KBr}, \mathrm{cm}^{-1}\right): 1504,1435,1282 .{ }^{1} \mathrm{H}$ NMR: 3.15 (pseudo-q, $J=6.20 \mathrm{~Hz}, 2 \mathrm{H}, \mathrm{CH}_{2} \mathrm{CH}_{2} \mathrm{Br}$ ), 3.28 (t, $J=5.9 \mathrm{~Hz}, 2 \mathrm{H}, \mathrm{CH}_{2} \mathrm{Br}$ ), 6.97 (t, $J=$ $7.3 \mathrm{~Hz}, 1 \mathrm{H}, \mathrm{CHTz}), 8.01$ [s, 2H, H3 (Tz)], 8.42 [s, 2H, H5 (Tz)]. ${ }^{13} \mathrm{C}$ NMR: $26.77\left(\mathrm{CH}_{2} \mathrm{Br}\right), 35.6$ $\left(\mathrm{CH}_{2} \mathrm{CH}_{2} \mathrm{Br}\right), 69.9\left(\mathrm{CHTz}_{2}\right), 143.2[\mathrm{C5}(\mathrm{Tz})], 152.8$ [C3 (Tz)]. MS (EI), m/z: 256.0 [M] $]^{+}, 258.0$ $[\mathrm{M}+2]^{+}$. Anal. Calc. for $\mathrm{C}_{7} \mathrm{H}_{9} \mathrm{BrN}_{6}(257.09) \mathrm{C}, 32.70 ; \mathrm{H}, 3.53 ; \mathrm{N}, 32.69 \%$. Found: $\mathrm{C}, 32.43 ; \mathrm{H}$, $3.21 ; \mathrm{N}, 32.87 \%$.

3,3-Bis(1,2,4-triazol-1-yl)-1-propyl mesylate (5). A stirred mixture of 3 (200 mg, $1.03 \mathrm{mmol})$ and $\mathrm{Et}_{3} \mathrm{~N}(215 \mu \mathrm{L}, 1.55 \mathrm{mmol})$ in THF $(40 \mathrm{~mL})$ was cooled to $0{ }^{\circ} \mathrm{C}$ and treated dropwise with a solution of freshly distilled $\mathrm{MsCl}(177 \mathrm{mg}, 1.55 \mathrm{mmol})$ in THF $(10 \mathrm{~mL})$. The mixture was allowed to warm up to room temperature for a further $2 \mathrm{~h} . \mathrm{Et}_{3} \mathrm{~N} \cdot \mathrm{HCl}$ was then removed by centrifugation and the solvent evaporated under vacuum. Compound $\mathbf{5}$ was obtained as an oil after chromatography $\left(\mathrm{SiO}_{2}, \mathrm{CH}_{2} \mathrm{Cl}_{2} / \mathrm{EtOH}, 25: 1\right)$. Yield 96\%. IR (THF, $\left.\mathrm{cm}^{-1}\right)$ : 1506, 1417, 1376, 1346. ${ }^{1} \mathrm{H}$ NMR: 3.03 (s, $\left.3 \mathrm{H}, \mathrm{CH}_{3}\right), 3.10\left(\mathrm{dt}, J=5.5 \mathrm{~Hz}, 7.3 \mathrm{~Hz}, 2 \mathrm{H}, \mathrm{CH}_{2} \mathrm{CH}_{2} \mathrm{O}\right), 4.21$ (t, $J=5.5$ $\left.\mathrm{Hz}, 2 \mathrm{H}, \mathrm{CH}_{2} \mathrm{O}\right), 6.87\left(\mathrm{t}, J=7.3 \mathrm{~Hz}, 1 \mathrm{H}, \mathrm{CHTz}_{2}\right), 8.01$ [s, 2H, H3 (Tz)], 8.40 [s, 2H, H5 (Tz)]. ${ }^{13} \mathrm{C}$ NMR: $33.6\left(\mathrm{CH}_{2} \mathrm{CH}_{2} \mathrm{O}\right), 37.6\left(\mathrm{CH}_{3}\right), 64.0\left(\mathrm{CH}_{2} \mathrm{CH}_{2} \mathrm{O}\right), 68.0\left(\mathrm{CHTz}_{2}\right), 143.3[\mathrm{C} 5(\mathrm{Tz})], 152.9$ [C3 (Tz)]. MS (EI), m/z: $272.1[\mathrm{M}]^{+}$.

Dendron 7. A mixture of 5 (150 mg, $0.55 \mathrm{mmol})$, 3,5-dihydroxybenzyl alcohol (39 $\mathrm{mg}, 0.27$ $\mathrm{mmol})$, dry potassium carbonate $(208 \mathrm{mg}, 1.50 \mathrm{mmol})$ and 18 -crown-6 $(5 \mathrm{mg}, 0.02 \mathrm{mmol})$ in dry THF (15 mL) was heated under reflux and stirred vigorously under argon for $16 \mathrm{~h}$. The mixture was allowed to cool to room temperature, filtered and evaporated to dryness under reduced pressure. The crude product was purified by chromatography $\left(\mathrm{SiO}_{2}, \mathrm{CH}_{2} \mathrm{Cl}_{2} / \mathrm{EtOH}, 25: 1\right)$ followed by crystallization from $\mathrm{CH}_{2} \mathrm{Cl}_{2} / \mathrm{CCl}_{4}$ to give 7 as a colorless solid. Yield $75 \%$. mp: 140$142{ }^{\circ} \mathrm{C} .{ }^{1} \mathrm{H}$ NMR: 3.10 (q, $J=5.5 \mathrm{~Hz}, 4 \mathrm{H}, \mathrm{CH}_{2} \mathrm{CH}_{2} \mathrm{O}$ ), 3.68 (s, $\left.1 \mathrm{H}, \mathrm{OH}\right), 3.89$ (t, $J=5.3 \mathrm{~Hz}, 4 \mathrm{H}$, $\left.\mathrm{CH}_{2} \mathrm{CH}_{2} \mathrm{O}\right), 4.61\left(\mathrm{~s}, 2 \mathrm{H}, \mathrm{CH}_{2} \mathrm{OH}\right), 6.22$ (t, $J=2.2 \mathrm{~Hz}, 1 \mathrm{H}, \mathrm{CH}-$ para), 6.46 (d, $J=1.8 \mathrm{~Hz}, 2 \mathrm{H}$, CH-ortho), $6.98\left(\mathrm{t}, J=5 \mathrm{~Hz}, 2 \mathrm{H}, \mathrm{CHTz}\right.$ ), 8.00 [s, 4H, H3 (Tz)], $8.41[\mathrm{~s}, 4 \mathrm{H}, \mathrm{H} 5(\mathrm{Tz})] .{ }^{13} \mathrm{C}$ NMR: $33.4\left(\mathrm{CH}_{2} \mathrm{CH}_{2} \mathrm{O}\right), 62.4\left(\mathrm{CH}_{2} \mathrm{CH}_{2} \mathrm{O}\right), 64.8\left(\mathrm{CH}_{2} \mathrm{OH}\right), 68.6\left(\mathrm{CHTz}_{2}\right), 100.6(\mathrm{C}-$ para $), 105.5$ (C-ortho), 143.1 [C5 (Tz)], 144.1, 152.7 [C3 (Tz)], 159.2. MS (EI), m/z: $492.2\left[\mathrm{M}^{+}\right.$. 


\section{Acknowledgements}

This work was supported by the Consejería de Educación y Ciencia de Castilla-La Mancha (Projects PAI-02-016 and GC-02-013). J. G. is indebted to the Junta de Comunidades de Castilla-La Mancha for a grant.

\section{References and Notes}

1. Tang, L.-F.; Wang, Z.-H.; Chai, J.-F.; Leng, X.-B.; Wang, J.-T.; Wang, H.-G. J. Organomet. Chem. 2002, 642, 179.

2. (a) Ofele, K.; Herrmann, W. A.; Mihailos, D.; Elison, M.; Herdtweck, E.; Scherer, W.; Minki, J. J. Organomet. Chem. 1993, 459, 177. (b) Bertrand, G.; Díez-Barra, E.; FernándezBaeza, J.; Gornitzka, H.; Moreno, A.; Otero, A.; Rodríguez-Curiel, R. I.; Tejeda, J. Eur. J. Inorg. Chem. 1999, 1965. (c) Herrmann, W. A.; Schawarz, J.; Gardiner, M. G.; Spiegler, M. J. Organomet. Chem. 1999, 575, 80. (d) Mata, J. A.; Peris, E.; Incarvito, C.; Crabtree, R. Chem. Commun. 2003, 184.

3. Díez-Barra, E.; Guerra, J.; Hornillos, V.; Merino, S.; Tejeda, J. Tetrahedron Lett. 2004, 45, 6937.

4. (a) Díez-Barra, E.; García-Martínez, J. C.; Guerra, J.; Hornillos, V.; Merino, S.; del Rey, R.; Rodríguez-Curiel, R. I.; Rodríguez-López, J.; Sánchez-Verdú, P.; Tejeda, J; Tolosa, J. ARKIVOC 2002, 17. (b) Díez-Barra, E.; Guerra, J.; Rodríguez-Curiel, R. I.; Merino, S.; Tejeda, J. J. Organomet. Chem. 2002, 660, 50.

5. In a previous paper we reported that the bis(triazolium)methylene system is readily cleaved by alcohols. Díez-Barra, E.; de la Hoz, A.; Rodríguez-Curiel, R. I.; Tejeda, J. Tetrahedron 1997, 53, 2253.

6. Hawker, C. J.; Fréchet, J. M. J. J. Am. Chem. Soc. 1990, 112, 7638. 